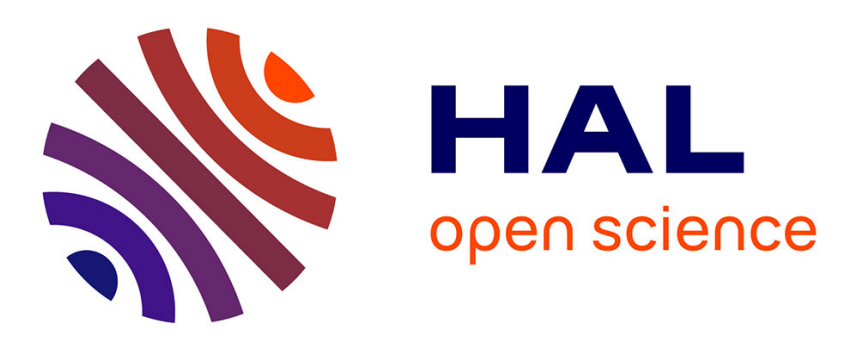

\title{
Educational Support on Computing and Informatics as Means of Empowering Disadvantaged Young People in Developed Countries
}

Toshinori Saito

\section{- To cite this version:}

Toshinori Saito. Educational Support on Computing and Informatics as Means of Empowering Disadvantaged Young People in Developed Countries. 11th IFIP World Conference on Computers in Education (WCCE), Jul 2017, Dublin, Ireland. pp.515-524, 10.1007/978-3-319-74310-3_52 . hal01762848

\author{
HAL Id: hal-01762848 \\ https://hal.inria.fr/hal-01762848
}

Submitted on 10 Apr 2018

HAL is a multi-disciplinary open access archive for the deposit and dissemination of scientific research documents, whether they are published or not. The documents may come from teaching and research institutions in France or abroad, or from public or private research centers.
L'archive ouverte pluridisciplinaire HAL, est destinée au dépôt et à la diffusion de documents scientifiques de niveau recherche, publiés ou non, émanant des établissements d'enseignement et de recherche français ou étrangers, des laboratoires publics ou privés.

\section{(c)(1)}

Distributed under a Creative Commons Attribution| 4.0 International License 


\title{
Educational Support on Computing and Informatics as Means of Empowering Disadvantaged Young People in Developed Countries
}

\author{
Toshinori Saito \\ Graduate School of Practitioners in Education, Seisa University, Kanagawa, Japan \\ t-saito@gred.seisa.ac.jp
}

\begin{abstract}
The paper discusses a research into civil empowerment in a developed country through promoting learning opportunities of computing and informatics based on a question as follows: What kind of possibility and limitation can be found in educational support on computing and informatics as a means of empowerment and social inclusion of socially disadvantaged youths in developed countries? For the question, following action research methodology, the author had joined a group's activity of helping social participation of disadvantaged youths in a mid-sized city in Japan and engaged in supporting learning computing. We found that creative aspects of computing had involved the youths into autonomous learning of computing; however, their expanded capacities of computing hadn't obviously been converted into their motivation for social participation. It suggests that more holistic support enabling them to find the meaning of learning computing in context should be designed and practiced for their further empowerment.
\end{abstract}

Keywords. Computing and informatics ' socially disadvantaged learners · educational support $\cdot$ social inclusion · empowerment

\section{Introduction}

Global disemination of information and communication technologies (ICTs) was supposed to lead to development and reinforcement of global democracy [1]. However, despite the global disemination of ICTs, realization of equitable enjoyment of its benefit is still seen problematic. Instead of promoting democratic values through the disemination of ICTs, the digital divide has been reported emerging and widening [2].

Accordingly, in pursuit of the framework for approaching the digital divide especially in developed country's setting, the paper presents a discussion on civil empowerment and social inclusion through promoting learning opportunities of computing and informatics. The discussion is based on a research project in progress conducted in a small-scaled support group for students with school absenteeism and socially withdrawn youths $[3,4]$. The group is placed in a mid-sized provincial city in Japan.

The purpose of the research is to advance understanding of the significance of promoting learning opportunities of computing and informatics in terms of civil 
empowerment and social inclusion. The research was conducted in accordance with the research question as follows:

- What kind of possibility and limitation can be found in educational support on computing and informatics for socially disadvantaged youths in developed countries as a means of empowerment and social inclusion?

\section{Relevant Literatures}

Concerning the discussion on tackling of the digital divide, the focus of discussion has now moved from achieving equal access to ICTs with providing physical infrastructures toward delivering equitable opportunities for citizens to enjoy substantial improvement of well-being through the empowerment on technology use [2], [5,6]. Empirical researches on the digital divide have revealed the factors that may affect citizens' disparity not only in access but also in use of ICTs, namely, race, ethnicity, gender, class, educational background, and other factors relating to the socioeconomic situations $[7,8,9,10,11]$. These factors commonly reflect social, economical, cultural, and historical circumstances of the society, which may form the background of the disparity between the 'haves' and the 'have nots' among citizens.

Results of the prior research have also led to the shared recognition that approaching the digital divide should be based on the conception of empowerment, which is directed toward fostering human capacities for living well thorough making good use of ICTs [12,13,14,15]. The conception of empowerment as a basis for tackling the digital divide can be applied to the situation not only in developing countries but also in developed countries, since it is common for both of the countries to have social structures reproducing socially disadvantaged members at risk of being excluded from informatized situation of the society [16]. In terms of the empowerment for such members in a society, the problem of digital divide can be understood intrinsically as a subset of so-called social exclusion, which is asking for the promotion of equitable opportunities for digital participations [17]. This means it is crucial to construct a blueprint of social inclusion into informatized societies under the circumstance of the globalized digital divide.

The research question shown above is informed with the outcome of preceding research on information and communication technologies for development (ICT4D). Many of the literatures on ICT4D insist on the indirectness between ICTs as technological input and enhancement of the residents' well-being as its output. Through the research on ICT development for rural communities in Bolivia, Gigler [12], [14], [18] emphasized that no direct relations had been found between improved ICT access and enhanced socio-economic development. In addition, using the notion of 'catalyst', Gigler argued the significance of 'intermediary organizations' in converting ICT access into 'meaningful use' of ICTs through educational support for the rural poor citizens. With the model of the ICT4D value chain, Heeks $[19,20]$ also argued the indirect relationship between ICT infrastructure and development impacts, which indicated the ICT access should be seen as merely a 'starting point in understanding ICT's contribution to development' [20]. 
The problem of the indirectness between ICT access and enhancement of residents' well-being is supposed to be common toward the developed countries where ICT diffusion has mostly been completed. This indirectness is basically affected by the social structure reflecting inequality and inequity in obtaining learning opportunity of computing and informatics, which is seen not only in developing countries but in developed countries (e.g. [8]). Though the state of basic literacy is generally better in developed countries, the distribution of learning opportunities to convert ICT access into meaningful use of ICTs is still left to be insufficient (e.g. [21]).

Furthermore, the research question is basically asking about the roles of computing and informatics education on the disadvantaged citizens' empowerment in informatized societies. The preceding arguments $[22,23,24]$ have shown the roles of such education in introducing fundamental concepts of computing and informatics and in expanding human capacities necessary to utilize ICTs effectively for various purposes. The arguments also have reported that expanding such capacities enabled people to produce systematic ways of problem-solving with ICTs and to create representations reflecting their own ideas. The role in expanding career choice with the enhancement of computing skills has also been discussed in some literatures (e.g. [23], [25]). There is, in addition, an argument which illustrates the educational role in promoting democratic participation, being considered as a basis of public education, through encouraging creating programs to contribute to others in the society [26].

However, the role of computing and informatics education hasn't been investigated and discussed adequately yet, especially in terms of empowering disadvantaged citizens living in informatized developed countries. We believe that such investigation and discussion will add an alternative view of computing and informatics education's contribution toward the realization of digital equity.

\section{Methodologies}

To explore the research question, the author joined a group's activity to help rehabilitation and social participation of the pupils and students with school absenteeism and the youths who had experienced socially withdrawal. The group was placed in a mid-sized provincial city in Japan. The group's size had varied during the research period, however, there were around 5 to 10 young people with 2 to 5 staff members including part time supporters. The author acted as a part time member mainly to support such youths in getting familiar with computing and in learning something about computing and informatics. As a data collection the author had made a series of text descriptions with some pictures and movies in the field, that was the author thought as field notes, noting events and occurrences, dialogues with group's participants, findings and interpretations, and reflections on every session during the research period. The data were analyzed into important themes and issues in accordance with the research question. This process was supplemented with further observations and dialogues in the field.

The research was conducted in May 2015, after a period of pilot study in the same field from December 2013 to January 2014, and still continues at present. This paper reports the findings based on the analysis of the field notes taken from May 2015 to March 2017. During the period, we, the author and the young people in the group, had 
been involved in learning introductions of computing and informatics with several practices, such as making games, teaching elderly people programming with Scratch, and constructing a programmable robot called MugBot ${ }^{1}$.

The research followed the basic conceptions of action research as a participatory research methodology. Action research is explained as an approach "that enables people to find effective solutions to problems they confront in their everyday lives" [27] by collaborative commitment toward real social problems for a group of people that are relevant to the problems. In this methodology, the researcher is not merely an objective observer but a member who actively participate in the process of problemsolving. Moreover, the research process is interpreted as a process seeking for positive social change based on democratic values [28]. The author applied the conceptions of action research for the research question called for practical engagement in an educational support project practiced in a real context of a developed country.

\section{Findings}

\subsection{The possibility of educational support on computing and informatics}

Firstly, we will examine the findings which suggest the possibility of educational support on computing and informatics as a means of empowerment and social inclusion of the youths in the group.

While joining the group's activity the author had met certain amount of young people who were at various range of the ages (from elementary pupils to late 20's). Among them the author had built a continuous relationship with two young people who were supported in the group for their rehabilitations. Both of them were male of late 20's had experienced the status of social withdrawal in years past and hadn't have any opportunity of regular employment (in the paper they are named as "M01" and "M02" for anonymization).

Based on the reflection and interpretation of the involvement with them, which had been noted in the field notes and other visual materials, the author found these suggestions shown below relating to the possibility of educational support on computing and informatics.

- With some triggers (e.g. suggestions on the joy of making games with programming, the way of obtaining teaching materials and other useful information in the web, and the annual event on Scratch programming) brought by the author, they got interested in using computers in more creative ways and autonomously engaged in learning computing.

- They were also motivated to learn introductory part of informatics and succeeded in finding the joy of learning it.

- During the period that they were learning and practicing computing and informatics in the group, they enjoyed the chances to communicate with others

1 MugBot is a nonproprietary open source social robot originally designed by Koike Laboratory in Tokyo Metropolitan University. http://www.mugbot.com 
(e.g. support staffs, other young participants, neighboring residents participated as volunteer supporter, and the pupils and students of the schools around) for their capacities of computing and informatics.

For instance, the author had noted in the field notes the circumstance in which the group members' had decided to engage in constructing MugBot. It shows how the members' emerging interests into creative aspects of computing had involved them into learning computing:

- Excerpt 1: Though my suggestion being one of the causes for them (includes M01, M02, and two other staffs of the group) to start the activity of making MugBot, more directly it has started by their own decision made after the participation of "Scratch Day in Tokyo 2016", at which they visited the booth presenting MugBot and felt very interesting with it. ${ }^{2}$

Actually, after that, M01 and M02 had begun to construct a unit of MugBot in early September of 2016 and kept their effort to complete all of the process of construction. Then they finally succeeded in completing the construction and controlling all of the basic functions (blinking eyes of LED, voicing given text data, and moving its head according to given programs) in late December. While they were engaged in it, they supposed to learn controlling devices with programs and had experienced constructing an example of network system, which requires basic understanding of the Internet Protocol, merely with a textbook and other resources they found themselves. Very occasionally, the author gave advices when they seemed to get into difficulties that might be beyond their capacities.

Moreover, their capacities of computing and informatics had become a cause of generating new communication with others visited their working space. For instance, when the group accepted two students of a junior high school located near the group's space for the students' work experience program in the school, M01 had autonomously attempted to introduce making programs with Scratch toward the students. To the author's eyes the students' time for work experience program seemed to become more meaningful and more pleasurable for it. The author described this incident in the field notes as shown below:

- Excerpt 2: (1) I (the author) left how the progression (of introducing programming to the students) should be to M01's judge. Then M01 took an introductory algorithm book and handed it to the students. (2) M01 sat besides the students and sometimes gave suggestions to them. One of the students showed a smile on his face. (3) The way M01 introduced programming to the students can apparently be interpreted as an inclusion for the students into the culture of programming (suppose there is something like that). ${ }^{3}$

2 It is extracted from the field notes written in 25th August 2016. The whole part of the field notes is written in Japanese and all of the quoted parts in this paper are English translation of the original field notes.

3 All of the quoted part is from the field notes written in $19^{\text {th }}$ January 2017. 


\subsection{Limitations of educational support on computing and informatics}

The author also found these suggestions, as a result of the reflection on the field notes, concerning limitations of educational support on computing and informatics.

- The young people's expanded capacities of computing and informatics didn't seem to expand obviously their motivation for making use of such capacities for their social participation to improve their personal situation in the surrounding society.

- Their motivation for making use of such capacities to improve circumstances of the community they belonged to also didn't manifest itself in their behavior.

- It seemed difficult for the group members (including the support staffs) to convert efficiently such capacities they had made into the group's competence.

With regard to the first and the second points, there is a description of the author's consideration over an incident happened in the field:

- Excerpt 3: As we have seen in today's practice, the aim (of the practice) 'creating programs which can afford someone a certain level of convenience' itself is substantially social in terms of supposing a real context by considering 'someone' and 'a certain level of convenience'. Moreover, the activity of 'making a process of a task more efficient (or offering a pleasure to someone) by creating a program' is unavoidably a social practice because it needs a setting of others (or a self as an object in the context of society). The reason why M01 consistently tells 'I have no interest in doing it' or 'I am not good at doing it' seems to reflect his strong refusal of engaging in the activity that requires being social. ${ }^{4}$

The incident based on the consideration above was that M01 showed negative attitude toward the author's offer of creating a program based on his own or the group's needs of computing. M01 was quite positive when he had leaned and reproduced programs according to some situation-settings given by the textbooks. In addition, M01 seemed to have enjoyed learning an introductory level of informatics with making programs according to the instruction in the textbooks. However, M01 had consistently expressed his indifference to create something which could be a solution for 'real problems' concerning his personal or the group's daily activities making use of his capacity of computing.

The third point had related to the limitation of the members' participation in the educational support. The group was mainly managed by two core staffs, who were the manager and the co-manager of the group, with the help of several volunteer staffs (M01 had changed his position in the group from a supported member toward a volunteer stuff during the research period. He had been virtually supported in his social participation while working as a volunteer stuff). In the author's view, they had had a shortage in staffs for the amount of their tasks, which made it difficult to involve themselves into the practice of computing and informatics as much as they could develop their own educational support programs by themselves.

Concerning the supported members, the author and the staffs (especially M01 and the manager of the group) had provided various occasions for them to encounter the

4 The quoted part is from the field notes written in $16^{\text {th }}$ Februaly 2017. 
practice of computing, mainly with Scratch programming as an introduction. And actually, many of them seemed to be interested in practicing computing. However, the membership of the supported members had not been stable because of their participation in the group was basically left to their own circumstances, which were sometimes too complicated socially and personally to keep attending the practice.

\section{Discussion and conclusion}

We finally propose following suggestions obtained regarding the possibility of educational support on computing and informatics based on the findings of the field research. The suggestions are that (1) such support can expand the mode of disadvantaged youths' daily use of ICT facilities; (2) it also can derive their desire for personal challenges of autonomous expansion of their computing capacity; (3) it can enlarge the youths' communication opportunities with others around. Concerning the suggestion (1), the youths in the observed group had successfully learned to enjoy utilizing ICT facilities in more creative ways with programming whereas they at first had very limited idea to utilize them because of their limited learning opportunity for the personal and social circumstances. Concerning the suggestion (2), promotion of the autonomous behavior in learning computing had commonly been observed in both M01 and M02's usual practices during the research period. Concerning the suggestion (3), such communication opportunities were observed among them with the staff members, volunteer supporters, other youths in the group, visiting residents, and so forth, which had occurred in the context of computing practices.

On the other hand, we have to propose following suggestions regarding the limitations of the educational support based on the findings. The suggestions are that (1) such support cannot turn disadvantaged youths' expanded capacities of computing directly into the ideas of applying it toward real problem solving activities in social situations; (2) it also cannot enhance the youths' motivation for utilizing their computing capacities into strengthening their connections with societies around; (3) it cannot function without continuous help of volunteer supporters who have computing capacities and are ready for work with practitioners in the field. Concerning the suggestion (1), both M01 and M02 had consistently shown quite reserved attitudes to engage in solving problems relating to the group's activities utilizing their computing capacities. Concerning the suggestion (2), on M01 and M02's case, strengthening of the connections with societies in this term had potentially contained seeking jobs, attempting to learn in higher education, creating the group's new activity to contribute toward neighboring communities, and so force. In the research period any obvious incidents relating to these hadn't be observed. Concerning the suggestion (3), it should be noted that, as far as the reported research period, most part of the educational support in the group had maintained mainly with the author's participation.

The obtained suggestions lead two conclusions. One is that, premising collaboration of the practitioners of both computing and social participation support backgrounds, educational support on computing and informatics for disadvantaged youths in developed country has a certain potential of expanding their choice of meaningful use of ICTs with deriving autonomous participation in computing 
practices. This conclusion is consistent with the recent tendency of digital divide research which emphasizes the gap of 'meaningful use' rather than 'physical access' as a key factor of approaching inequitable circumstances of ICT use (e.g. [17], [29]). Moreover, this conclusion corresponds with an ICT4D's evaluation framework, the 'Choice Framework' proposed by Kleine [30], which argues the significance of small case development studies on ICTs' role of expanding freedom of residents' choice as empowerment [20].

Another is that, the educational support cannot be the solo factor to encourage them in their social participation through utilizing their computing capacities. We suppose that there will be a limitation within such educational support in terms of empowerment for social participation if computing and informatics are to be taught and learned merely as a value-free decontextualized knowledge by the learners. In other words, potential of the educational support to overcome the indirectness between ICT access and enhancement of residents' well-being should be understood restrictedly for the present. This is consistent with the indication made by Gigler [14] that "improving the access to resources for the poor, for instance providing access to girls' education or access to ICTs only represents a potential for enhancing their capabilities and thus does not automatically have to lead to positive outcomes on empowerment."

Nevertheless, this does not mean educational support on computing and informatics is absolutely unsuitable for the empowerment of disadvantaged youths' social participation since there is room for improvement in its pedagogical design to link the supported youths with the context of surrounding societies through utilizing computing capacities. From the author's viewpoint, the shown limitation rather signifies a demand for the educational support designed based on more social and contextual conceptions that can afford the supported youths an idea (or ideas) about engaging with societies utilizing their computing capacities. In this direction, Schultz's literature [31] will be one of the bases to pursue the possibility of computing education in the light of learner's social participation.

The educational support will continue for the purpose of investigating further affect on the youths and also on the group's activity. Therefore the author presents some insights derived as recommendations for the continuous educational support; practices in the support should be designed considering involving the youths into computing in context so as to make more opportunities to link their capacities toward real needs of computing; the 'real needs' for computing capacities should be explored under the dialogical relationship among the youths, the practitioners, and the researcher; for the pursuit of sustainable support, an institutional framework to include the support group into decent computing culture should be explored. In other words, more holistic support, containing some active problem-solving projects utilizing computing capacities for instance, that enables the supported youths to find the meaning of learning computing in context should be explored and practiced for further empowerment.

Acknowledgments. The author would like to thank all of the members of the support group who kindly gave the opportunity to conduct the field sessions. The research was supported by JSPS KAKENHI Grant Number 16K01136. 


\section{References}

1. Ferdinand, P.: The Internet, Democracy and Democratization. Democratization. 7:1, 1-17 (2000).

2. Revenaugh, M.: Beyond the Digital Divide: Pathways to Equity.Technology \& Learning. (1), 38-50 (2000).

3. Tateno, M., Park, T.W., Kato, T. a, Umene-Nakano, W., Saito, T.: Hikikomori as a possible clinical term in psychiatry: a questionnaire survey. BMC Psychiatry. 12, 169 (2012).

4. Tajan, N.: Japanese post-modern social renouncers : An exploratory study of the narratives of Hikikomori subjects. Subjectivity. 8, 283-304 (2015).

5. Warschauer, M.: Reconceptualizing the digital divide. First Monday. 7, (2002).

6. Warschauer, M.: Technology and Equity in Schooling: Deconstructing the Digital Divide. Educ. Policy. 18, 562-588 (2004).

7. Clark, C., Gorski, P.: Multicultural education and the digital divide: Focus on socioeconomic class background. Multicult. Perspect. 4, 25-36 (2002).

8. Kvasny, L.: Cultural (re) production of digital inequality in a US community technology initiative. Information, Commun. Soc. 9, 160-181 (2006).

9. Gudmundsdottir, G.: From digital divide to digital equity: Learners' ICT competence in four primary schools in Cape Town, South Africa. Int. J. Educ. Dev. using ICT. 6, 84-105 (2010).

10. Ritzhaupt, A., Liu, F.: Differences in student information and communication technology literacy based on socio-economic status, ethnicity, and gender: Evidence of a digital divide in. J. Res. Technol. Educ. 45, 291-307 (2013).

11. Willis, S., Tranter, B.: Beyond the "digital divide": Internet diffusion and inequality in Australia. J. Sociol. 42, 43-59 (2006).

12. Gigler, B.-S.: Including the Excluded- Can ICTs empower poor communities? Towards an alternative evaluation framework based on the capability approach. In: 4th International Conference on the Capability Approach Vol. 5, No. 7, September, 2004 University of Pavia, Italy (2004).

13. Johnstone, J.: Technology as empowerment: a capability approach to computer ethics. Ethics Inf. Technol. 9, 73-87 (2007).

14. Gigler, B.-S.: Informational Capabilities-The Missing Link for the Impact of ICT on development. World Bank ICT Sect. Week . E-Transformation Work. Pap. Ser. World Bank Work. Pap. Ser. (2011).

15. Simsek, E., Simsek, A.: New Literacies for Digital Citizenship. Contemp. Educ. Technol. 4, 126-137 (2013).

16. Selwyn, N.: Reconsidering Political and Popular Understandings of the Digital Divide. New Media Soc. 6, 341-362 (2004).

17. Wei, L., Hindman, D.B.: Does the Digital Divide Matter More? Comparing the Effects of New Media and Old Media Use on the Education-Based Knowledge Gap. Mass Commun. Soc. 14, 216-235 (2011).

18. Gigler, B.: Poverty, inequality and human development of indigenous peoples in Bolivia. (2009).

19. Heeks, R., Molla, A.: Impact Assessment of ICT-for-Development Projects: A Compendium of Approaches. University of Manchester, UK (2009).

20. Heeks, R.: Do information and communication technologies (ICTs) contribute to development? J. Int. Dev. 22, 625-640 (2010). 
21. European Commission.; The International Computer and Information Literacy Study (ICILS): Main findings and implications for education policies in Europe. (2014). http://ec.europa.eu/dgs/education_culture/repository/education/library/study/2014/ecicils_en.pdf

22. Resnick, M., Flanagan, M., Kelleher, C., MacLaurin, M., Ohshima, Y., Perlin, K., Torres, R.: Growing Up Programming Democratizing the Creation of Dynamic, Interactive Media. In: CHI EA '09 Proceedings of the 27th international conference extended abstracts on Human factors in computing systems, April 4-9, 2009, Boston, Massachusetts, USA. pp. 3293-3296 (2009).

23. Hromkovič, J., Steffen, B.: Why Teaching Informatics in Schools Is as Important as Teaching Mathematics and Natural Sciences. In: Informatics in Schools. Contributing to 21st Century Education: 5th International Conference on Informatics in Schools: Situation, Evolution and Perspectives, ISSEP 2011, Bratislava, Slovakia, October 26-29, 2011. Proceedings. pp. 21-30 (2011).

24. Sysło, M.M., Kwiatkowska, A.B.: Informatics for All High School Students A Computational Thinking Approach. In: Informatics in Schools. Sustainable Informatics Education for Pupils of all Ages: 6th International Conference on Informatics in Schools: Situation, Evolution, and Perspectives, ISSEP 2013, Oldenburg, Germany, February 26March 2, 2013. Proceedings. pp. 87-100 (2013).

25. Seehorn, D., Carey, S., Fuschetto, B., Lee, I., Moix, D., O’Grady-Cunniff, D., Owens, B.B., Stephenson, C.: CSTA K - 12 Computer Science Standards: Revised 2011. Academic Press (2011).

26. Schulte, C.: Reflections on the role of Programming in Primary and Secondary Computing Education. In: WiPSE '13: Proceedings of the 8th Workshop in Primary and Secondary Computing Education. pp. 17-24. ACM (2013).

27. Stringer, E. T.: Action research. Sage Publications, p.1 (2013).

28. Brydon-Miller, M., Greenwood, D., \& Maguire, P. (2003). Why Action Research? Action Research, 1(1), 9-28. doi:10.1177/14767503030011002

29. Warschauer, M.: Technology and Social Inclusion: rethinking the digital divide. p. 216. MIT Press, Cambridge Massachusetts (2003).

30. Kleine, D.: ICT4What ? - Using the Choice Framework to operationalise the Capability Approach to Development. J. Int. Dev. 22, 674-692 (2010).

31. Schulte, C.: Reflections on the role of Programming in Primary and Secondary Computing Education. In: WiPSE '13: Proceedings of the 8th Workshop in Primary and Secondary Computing Education. pp. 17-24. ACM (2013). 